\title{
Improving downhole pump efficiency and well productivity in heavy oil reservoirs utilizing back pressure regulator
}

\author{
Farshid Torabi • Benyamin Yadali Jamaloei • \\ Sam-Yeol Hong • Nadeem K. Bakhsh
}

Received: 19 March 2012/Accepted: 13 August 2012/Published online: 12 September 2012

(C) The Author(s) 2012. This article is published with open access at Springerlink.com

\begin{abstract}
A highly unconsolidated undersaturated reservoir producing heavy oil with an API of $12.1^{\circ}$ is located in Lindbergh Field of Elk Point area, Alberta, Canada. A specific well in this reservoir was initially designed to produce oil via a cold heavy oil production with sand (CHOPS) mechanism. However, a large amount of the sand production on a daily basis plugged the progressive cavity pump installed in the well. The cost of well services to unplug the pump on a monthly basis exceeded the revenue from produced oil, and thus, the well was considered uneconomic. Various techniques have been sought to control the sand production and to increase the cumulative oil production and the pump efficiency. Installing screens and meshes in the production interval of the wellbore was analyzed as a solution to the sand production. Installing screens increased the skin factor and resulted in a very low production rate of $0.15 \mathrm{~m}^{3} / \mathrm{day}$. The cost of purchasing and installing screens was estimated to be approximately $\$ 87,650$ with five shut-in days. In addition, the screens also needed further sand clean up, which is an expensive process. Hence, the screens were not recommended for this candidate well. A Back-pressure regulator (BPR) is currently installed on the casing of the well. The initial purpose
\end{abstract}

F. Torabi $(\bowtie) \cdot$ B. Yadali Jamaloei $\cdot$ S.-Y. Hong ·

N. K. Bakhsh

Petroleum Systems Engineering Department,

Faculty of Engineering and Applied Science,

The University of Regina, Regina, SK, Canada

e-mail: farshid.torabi@uregina.ca

Present Address:

B. Yadali Jamaloei

The Department of Chemical and Petroleum Engineering,

The Schulich School of Engineering, The University of Calgary,

Calgary, AB T2N 1N4, Canada of installing BPR on the casing was to control the wellbore pressure. The BPR restricts the flow of gas vented through the casing-tubing annulus. This study analyzes the effects of restricting flow of the vented gas such as solution gas reduction, which causes (i) higher settling velocity for the sand grain, (ii) lower Basic sediment and water (BS\&W), and (iii) lower in situ oil density. The production data of candidate well obtained from AccuMap (v.18.12) shows that the production hours increased significantly after installing BPR. This is because the number of well services reduced by $90 \%$. This results in an approximately $\$ 34,000$ per month increase in profit (assuming \$30.00/barrel of oil) for each well. This shows one million dollars savings on a monthly basis when the application of the BPR installation is implemented on 30 similar wells. The cost of the BPR installed on well is $\$ 328.00$, and there is no operating cost involved since the cost of additional, necessary maintenance and operation is nearly negligible. Moreover, this study provides the field examples of improper BPR operation, which resulted in economic loss. Possible solutions to fix the improper installation of BPR are proposed as well.

Keywords Back pressure regulator - Downhole pump efficiency $\cdot$ Sand production - Well productivity ·

Heavy oil reservoirs

\section{Introduction}

The Elk Point is one of the heavy oil fields in Alberta. Cold heavy oil production with sand (CHOPS) is the main recovery method applied in the area, along with the utilization of Progressive cavity pump (PCP). The development of CHOPS has become possible with the introduction of PCP. PCP is capable of lifting highly viscous mixture of oil 
and sand as opposed to conventional pumps. In spite of the PCP's suitability for handling significantly higher sand cut in viscous heavy oil, some wells in the Elk Point area require frequent well services due to excessively high sand production. From both the operation and production points of view, such well services have to be avoided as much as possible. This is because well services not only increase the operating costs but also reduce the production hours.

The well examined in this study is in the Elk Point area. This well is known as the 'trouble' well in this area. The 'trouble' here refers to the numerous well services that the well has entailed due to high sand production. This has resulted in a significant drop in its economic value. Various solutions, such as chemicals' injection, were experimented on well, and yet no successful result was found. Later, a Backpressure regulator (BPR) was installed on the casing-tubing annulus of the well to study its effect on the sand production.

One focus of this work was to provide a rigorous review and analysis of the approaches used in the petroleum industry for the sand production control in heavy oil reservoirs, which is missing from the literature. Moreover, this study sheds light on improving the downhole pump efficiency and well productivity in heavy oil reservoirs utilizing BPR, through a case study. This subject has not been discussed previously in the literature of subject. First, we review the reasons and consequences of sand production from the well and various techniques that can be used to control or minimize it. Then, traditional techniques of sand production control such as installing gravel packs, screens and meshes are reviewed with the an emphasis on the suitability of installing gravel packs and screen on the well. Furthermore, the BPR installation on the casing-tubing annulus is introduced and analyzed along with providing production data and economic analysis. Finally, a guideline for the operation of PCP and BPR is developed so as to help optimizing well production in the most economic fashion.

\section{Technical background}

CHOPS is the largest area of study and, therefore, must be discussed at the outset. The following discussion is especially focussed on PCP, which cannot be separated from the CHOPS process. In this discussion, the sand production problem that the candidate well has been facing is described in detail as well as the brief explanation of the PCP mechanism. The understanding of fluid level and well optimization are also required since it plays the most important role in the PCP operation. Last, the history of well is provided.

Cold heavy oil production with sand

Traditionally, CHOPS is one of the main recovery techniques in Canada. CHOPS is a non-thermal recovery technique used in unconsolidated/weakly consolidated heavy oil reservoirs, which enhances the oil recovery by simultaneous production of sand and oil. The intended sand production plays a very important role in the high productivity of CHOPS (Aghabarati et al. 2008). The effect of the sand production on the enhanced productivity in the CHOPS process is seen as a high negative skin effect in CHOPS wells. For example, the generation of Inflow performance curve (IPR) shows that the skin factor in the well under consideration is approximately -6.3 . In addition to the sand production, the other factor that contributes to the high productivity of CHOPS operations is the reduction in the in situ oil viscosity of the bitumen as a result of the 'foamy oil' phenomenon.

\section{Use of progressive cavity pump}

PCP is widely used along with Electric submersible pump (ESP) and Gas lift (GS) operation for CHOPS using artificial lift systems (Cavender 2004). The foremost advantage of utilizing PCP is the high capacity of lifting highly viscous mixture of oil and sand, which initially contributed to the development of CHOPS. The wide usage of PCP in CHOPS is also based on its higher volumetric efficiencies, lower lifting cost, lower capital cost, lower maintenance, application flexibility, and environmental benefits (Revard 1995).

In spite of the PCP's high capacity of handling sand, some wells in the heavy oil fields in Canada, such as the well under consideration, tend to experience an excessive inflow of sand beyond the pump capacity. When an excessive amount of sand flows into the wellbore, these accumulated sands must be physically removed. Well services, however, must be avoided as much as possible not only from the economical point of view but also from the operational point of view. In addition, dry operation has a significant impact on PCP. In order to prevent dry operation from occurring, the fluid level needs to be kept above the pump suction. In Section "Fluid level and well optimization", a discussion on fluid level and well optimization is provided.

Fluid level and well optimization

To obtain proper knowledge of the PCP operation, the applications of fluid level and the well optimization has to be understood. The fluid level refers to the liquid level in the annulus of a well, consisting of gas, oil, water, and sand. The fluid level in the casing is utilized to estimate the wellbore pressure as follows:

$P_{\mathrm{wf}}=P_{\mathrm{c}}+\rho_{\mathrm{g}} g h_{\mathrm{g}}+\rho_{\mathrm{l}} g h_{\mathrm{l}}$

where $P_{\mathrm{wf}}$ is the wellbore pressure, $P_{\mathrm{c}}$ is the casing head pressure, $\rho_{\mathrm{g}}$ is the gas density in the casing, $\rho_{1}$ is liquid density in the casing, $h_{\mathrm{g}}$ is the gas column height in the 
casing, and $h_{1}$ is the liquid column height in the casing. When the wellbore pressure is minimized, the production is maximized. According to Eq. 1, this is the condition when the lowest $P_{\mathrm{c}}$ and no liquid column (i.e. $h_{1}=0$ ) exist. In the Elk Point area, the casing was always opened to the atmosphere to achieve the lowest $P_{\mathrm{c}}$.

Given these adverse effects of ' $h h_{1}=0$ ' from the production and operational points of view, the ideal operating condition is obtained when the fluid level is kept right at the pump suction. This will allow the lowest wellbore pressure to be achieved without generating dry conditions for the pump. In this case, the well is producing under an optimized condition.

\section{History of well}

The heavy oil well under consideration is currently producing from both formations of DINASD and CUMMGSS (or Wabiskaw-McMurray formation) The well is producing from the undersaturated reservoirs under the solution gas drive mechanism with no support from the gas cap or aquifer. The main recovery method in the Elk Point area is CHOPS using PCP. This well is known as one of the 'trouble' wells in the area due to the enormous sand production. This led to the inefficient PCP operation and corresponding decrease in the production, which in turn raised the need for an extraordinary number of well services. As a result, various experiments such as chemicals' injection were conducted so as to reduce the amount of sand flowing into the wellbore. However, none of the experiments resolved the problem. The last experiment is the installation of the BPR on the casing. The reservoir and fluid properties are given in Table 1.

\section{Sand production}

\section{Causes}

Sand production is a common problem particularly in shallow, unconsolidated reservoirs. The increased stresses due to fluid flow towards the production well and the pore

Table 1 Reservoir and fluid properties for the well

\begin{tabular}{ll}
\hline Reservoir pressure & $493 \mathrm{psia}$ \\
Reservoir temperature & $23{ }^{\circ} \mathrm{C}$ \\
Reservoir thickness $(h)$ & $9.16 \mathrm{~m}$ \\
Absolute rock permeability $(k)$ & $3,000 \mathrm{mD}$ \\
Average rock porosity $(\varnothing)$ & 0.32 \\
Drainage radius $\left(r_{e}\right)$ & $115.06 \mathrm{~m}$ \\
Wellbore radius $\left(r_{w}\right)$ & $0.089 \mathrm{~m}$ \\
${ }^{\mathrm{o}}$ API of crude oil & 12.1 \\
Oil formation volume factor $\left(B_{\mathrm{o}}\right)$ & $1.02 \mathrm{bbl} / \mathrm{STB}$ \\
\hline
\end{tabular}

pressure changes can exceed formation strength and initiate sand production (Penberthy and Shaughnessy 1992). The sand production increases with increase in production rate. Perforating the weaker reservoir rock can also increase sand production (Penberthy and Shaughnessy 1992). Many consolidated reservoirs show sand production after a considerable period of production due to pressure depletion, water production, increased fluid velocities, and decreased reservoir rock strength.

\section{Consequences}

Excessive sand production from a well has numerous economical, operational, environmental, and technical consequences. One of the main operational and economical issues involved with sand production is excessive pump servicing. The environmental concern is the removal of underground sand and its disposal. Treating the sand, repairing the pumps, installing special downhole and surface equipments, the separation process, and reduced oil production are some of the economical concerns. Productivity is also lost when a sand bridge forms in the production tubular (Penberthy and Shaughnessy 1992).

\section{Methods of control}

There are two general types of sand exclusion techniques (Golan and Whitson 1991): (i) mechanical and (ii) chemical. In the mechanical technique, a gravel pack is used to prevent the formation sand from entering the production tubing. The gravel is held by screens. Sometimes, screens alone are used to retain the formation sand. In the chemical technique, the strength of the formation is increased so that no formation sand enters into the production string. The following are the main techniques involved in sand control:

\section{Producing oil below critical flow rate}

This technique involves determining a critical production rate by testing and identifying sand production characteristics. In this method, production intervals are perforated with high-density shots per foot (8-12 shots per foot). However, it is recommended to perforate well-cemented sand intervals (Golan and Whitson 1991).

\section{Installing gravel pack and screen}

In some areas, a mechanical device such as a screen or slotted liner is placed in the perforated zones of the well and accurately sized gravel is placed around them. Therefore, when fluids pass through gravel pack, it restricts the flow of gravel/formation sand into the wellbore (Golan and Whitson 1991). If gravel packing is performed accurately, 
it will yield long-life and high productivity completions. In the steady-state flow condition, the skin term due to gravel pack for both oil and gas wells is given as (Golan and Whitson 1991)

$S_{\mathrm{G}}=96 \frac{\left(k / k_{\mathrm{G}}\right) \times h \times L_{\mathrm{p}}}{d_{\mathrm{p}}^{2} \times n}$

where $S_{\mathrm{G}}$ is the skin factor due to gravel packing, $k$ is the formation permeability in milliDarcy $(\mathrm{mD}), h$ is the formation thickness in $f t, k_{\mathrm{G}}$ is the gravel pack permeability in milliDarcy $(\mathrm{mD}), L_{\mathrm{p}}$ is the perforation depth in inches, $d_{\mathrm{p}}$ is the perforation diameter in inches, and $n$ is the total number of perforations.

\section{Chemically consolidating using resinous materials}

The resin consolidates sand together near the wellbore, forming a stable consolidated permeable rock mass. Injecting resins into the reservoir is done carefully to avoid considerable damage to the reservoir and incompatibility with the clays and minerals. Resins usually do not impair the reservoir permeability by more than $10 \%$ if injected properly (Golan and Whitson 1991).

\section{Designing gravel pack and screen for the candidate well}

Selecting the appropriate gravel pack technique

The inside-casing gravel packing is the best option for the candidate well for two reasons. First, it is mechanically reliable, and it would be convenient to install. Second, the gravels are not packed during completion of the well. Therefore, it is easier and quicker to perform the operation through workover since the well is already under production. It is also noted that the open-hole screen installation would not be a solution for this well because the completion is not open-hole. Even though the underreamed-casing gravel pack technique eliminates flow restriction, it can only be used at single-zone completions.

Parameters used to design screens

One of the important parameters used to design a screen is the ratio of gravel to formation grain size. Penberthy and Shaughnessy (1992) suggested the effective screen diameters for various sizes of casings. For a casing of seven inches (as in Well 2B-35-55-6), $2 \frac{7}{8}$ to $3 \frac{1}{2}$ inch screens were suggested.

Flow rate before and after screen installation

From the AccuMap database, the diameter of the casing was found to be $7.0 \mathrm{in}$. for the proposed well with a
Bottom-hole depth (BHD) of 668.12 feet. The well has a total perforated height of 13 in., equally distributed in two zones. From the production data of the well, the most recent $\mathrm{BS} \& \mathrm{~W}$ measurement shows $14 \%$ Water cut (WC \%) with $6 \%$ Sand cut (SC \%) and an average oil production rate $\left(Q_{t}\right)$ of $8 \mathrm{~m}^{3} /$ day. Hence

$$
\begin{aligned}
Q_{\text {net }} & =Q_{t}-\left(\mathrm{SC} \% \times Q_{t}+\mathrm{WC} \% \times Q_{t}\right) \\
& =8-(0.06 \times 8+0.14 \times 8)=6.4 \mathrm{~m}^{3} / \text { day }
\end{aligned}
$$

Assuming that the perforation fraction was 0.75 for the perforated zone, the water cut remains $14 \%$, and the change in production before and after installing screen can be calculated using Darcy's simplified equation for pseudo steady-state flow (Craft et al. 1990):

$$
Q_{1}=\frac{k h \Delta P}{141.2 B \mu\left(\ln \frac{r_{\mathrm{e}}}{r_{\mathrm{w} 1}}-\frac{1}{2}\right)}
$$

where $Q_{1}$ is the flow rate before installing screen in STB/ day; $k$ is the effective permeability in milliDarcy; $h$ is the reservoir thickness in feet; $\Delta P$ is the change in pressure in pounds per square inch; $B$ is the oil formation volume factor; $\mu$ is the oil viscosity of the oil in $c \mathrm{p}, r_{\mathrm{w} 1}$ is the radius of the well bore before installing screen in feet; and $r_{\mathrm{e}}$ is the radius of the reservoir in feet. After installing screen, the inflow area would be about $70 \%$ of the pipe surface area (Penberthy and Shaughnessy 1992).

After installing the screen, the difference in flow rate can be calculated as

$$
\frac{Q_{1}}{Q_{2}}=\frac{\frac{k h \Delta P}{141.2 B \mu\left(\ln \frac{r_{\mathrm{e}}}{r_{\mathrm{w} 1}}-\frac{1}{2}\right)}}{k h \Delta P}
$$

$Q_{1}=1.0529 Q_{2}$

where $Q_{2}$ is the flow rate after installing the screen in STB/ day, and $r_{\mathrm{w} 2}$ is the effective radius after the screen has been installed. Thus, the oil flowrate in the well decreased by approximately $5 \%$ when the screen was installed on the well. This will, however, increase the operating hours of the well without substantial increase in torque and, thus, reduce expenses on well services. On the other hand, there are huge expenses associated with installing screens, especially on wells that are on production.

Economic analysis of installing screen

In order to understand the economic advantages and disadvantages and to perform an economic analysis of installing screen, data for the well from one month has been used. All the well services were required because the pump could not function due to a large amount of sand production and, thus, resulting in sufficient decrease of 
pump efficiency and/or well shut-in. The well was also shut-in for 7 days due to sand issues and well services. The cumulative oil production for this particular well was $62 \mathrm{~m}^{3}$ for this particular month. Assuming an oil price of $\$ 30.00$ per barrel, the net income from the crude oil production would be $\$ 11,699.05$.

The net gain can be calculated from the expenses due to well services $(\$ 14,650.00)$. This indicates that $\$ 2,950.95$ was lost due to numerous well servicing and shut-in periods. Installing screens is, therefore, an alternative for sand issues with this well. The economic studies for installing screens are as discussed below.

The cost of the 250-micron mesh screen for the 7-in. casing of Well 2B-35-55-6 is $\$ 450.00$ per foot (source: Fitzpatrick, Halliburton), which totals $\$ 5,850.00$ for 13 feet of casing. The cost of the workover to remove the tubing and to install screens and packers/hangers approximately amounts to $\$ 80,000.00$. The installation would take about 5 days. Assuming an oil production rate of $51 \mathrm{bbl} /$ day and price of oil as $\$ 30.00$ per barrel, $\$ 7,650.00$ will be lost in the installation process. Hence, a total of $\$ 87,650.00$ is an approximate expense for installing screens. After screens are installed, there might be periods when screens need to be cleaned in case of plugging. This imposes an additional expense that needs to be considered as well. Due to the high oil viscosity, low oil flowrate, and high unconsolidated level of the reservoir, installation of screens is currently considered to be uneconomic.

Suitability of installing gravel pack and screen on well

CHOPS has been the primary mode of production due to the very high unconsolidated nature of the reservoir oil. In the CHOPS process, the decrease of skin factor and formation of wormholes in the reservoir is helpful for the oil production. However, when screens are installed on a well, skin factor increases due to the sand accumulation close to the screen and installation of gravel packs. Figure 1 compares the production rates for skin factors of 0 (gravel pack and screen have been installed) and -6.3 (normal production under CHOPS).

The skin factor of the well is estimated to be -6.3 . Figure 1 shows that when the skin factor is 0 , the maximum production rate is approximately $0.15 \mathrm{~m}^{3} /$ day, whereas it is $8.5 \mathrm{~m}^{3} /$ day when the skin factor is -6.3 . Therefore, installing gravel pack and screen on this well producing under CHOPS is not suitable.

\section{Application of BPR for heavy oil wells}

In this section, the application of BPR on casing of heavy oil wells is closely analyzed. The design of BPR

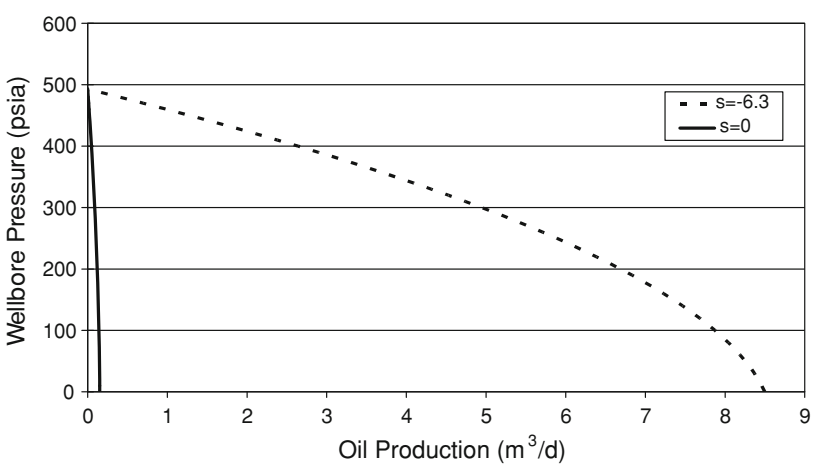

Fig. 1 Inflow performance curves of the candidate well

installation is described first. Subsequently, the function of the BPR installed on the casing is examined with close attention to the advantages and disadvantages of BPR installation. Based on the function of the BPR, the downhole mechanism that improves the pump efficiency is discussed. Finally, an economic analysis is conducted to study the potential economic value of the BPR installation.

\section{Design of BPR installation}

Figure 2 shows the simplified design of the wellhead when the BPR is installed. The safety tank (or pop tank) is not in place in the case of this well, but it is included as a recommendation because a high velocity gas may carry liquid to the surface, which will be spilled on the ground in the absence of this tank.

Function of BPR installed on casing

The function of BPR installed on the casing is to control the casing pressure, which in turn gives control over the wellbore pressure as the BPR restricts the flow of gas through the casing-tubing annulus. Without the BPR, the wellbore pressure is only controlled by the speed of the pump, as a higher speed lowers the wellbore pressure. From the producing perspective, higher pump speed or lower wellbore pressure is always preferred since it yields a higher production rate. However, in the case of 'trouble' wells such as such as the well under consideration, increasing the pump speed may result in the need for another well service, since the lower wellbore pressure results in a higher sand inflow. This shows that for this well, well optimization is not easily accomplished when the wellbore pressure is only a function of the pump speed. The foremost advantage of installing BPR on the casing is having control over the wellbore pressure. This advantage implies that the pump can be operated at a higher speed without lowering the wellbore pressure, which can now be controlled by BPR. A disadvantage of BPR installation is 


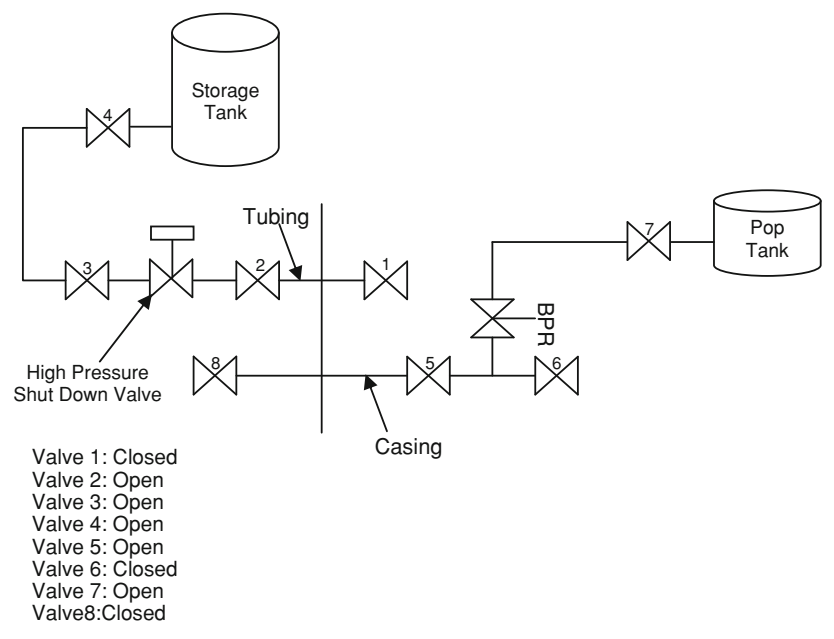

Fig. 2 Well head schematic

the decrease in the range of pump speed at which the pump can be operated without encountering the dry condition.

Downhole mechanism

In the Elk Point area, one side of the casing is usually operated as opened to the atmosphere (i.e., when Valve 6 is open in Fig. 2) to secure the fluid level in the casing. As shown in Fig. 3, if the casing is closed, the produced gas keeps being preserved in the casing, causing continuous build-up of the gas in the annulus. The liquid column is eventually pushed out by the increased height of the gas column, and consequently, the pump is operated under dry conditions. The main function of BPR here is to keep the casing pressure constant in a way that secures the fluid level and restricts the gas flow simultaneously.

Figure 4 depicts the flow path of two types of vented gas (i.e., solution gas and produced gas from the gas zone) from a saturated reservoir to the surface when BPR is installed. For a saturated reservoir, accurate measurements of Gas oil ratio (GOR) and the wellbore pressure are required to quantify the reduction in each type of vented gas. The quantification is important since it may be claimed that the BPR only causes solution gas reduction, as the level of free gas is not affected, or vice versa. However, a reasonable assumption here is that the reduced amount of the vented gas consists of not only one type of gas (i.e., solution gas) but also the other type of gas (i.e., produced gas from the gas zone or gas cap). In other words, the restriction of the flow of vented gas applies to both types of the produced gas at the surface. The following sections closely describe different effects of each gas type on the sand production.

Although the well is currently producing from the undersaturated reservoir, this study includes the effect of BPR on the produced gas from the gas zone (i.e., free gas

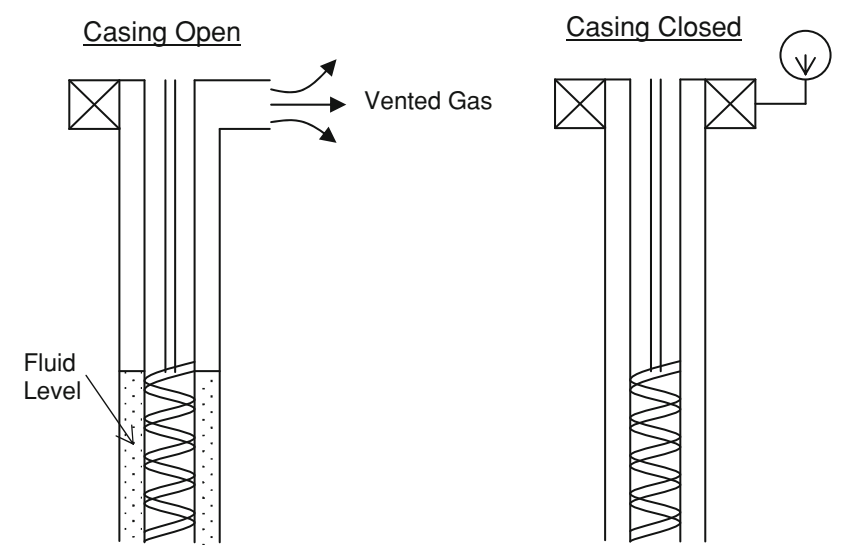

Fig. 3 Effect of closed casing on the dry operation

from gas cap) and the solution gas. It must be noted that for undersaturated reservoirs, only the solution gas reduction is affected by the BPR installation.

\section{Solution gas reduction}

The effects of solution gas reduction can be seen through (i) higher settling velocity of sand grains, (ii) lower Basic sediment and water (BS\&W), and (iii) lower in situ oil density. In this section, these effects are discussed.

Higher settling velocity of sand grains The definition of solution gas-oil ratio $\left(R_{\mathrm{S}}\right)$ is expressed as (McCain 1990)

$R_{\mathrm{s}}=\frac{\text { volume of gas produced at surface at standard conditions }}{\text { volume of oil entering stock tank at standard conditions }}$

Confusion may arise in an attempt to relate the effect of BPR with the above definition, as the actual value of $R_{\mathrm{s}}$ is not a function of casing pressure. In other words, the

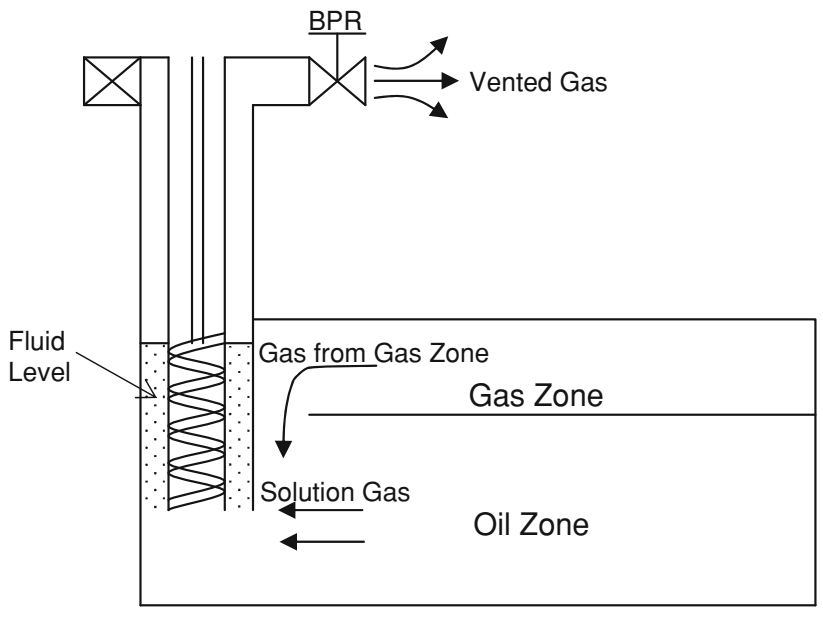

Fig. 4 Flow path of vented gas from reservoir to the surface when $\mathrm{BPR}$ is in place 
installation of BPR does not affect the actual value of $R_{\mathrm{S}}$ as defined above. Yet, the restriction of solution gas flow at an intermediate stage increases the amount of dissolved gas, and, therefore, increases the gas solubility at previous stages. Reducing the amount of solution gas vented through the casing results in higher gas solubility at wellbore conditions and, therefore, a higher value of $R_{\mathrm{s}}$. The oil viscosity decreases exponentially with increasing gas solubility when the pressure of interest is below the bubble point pressure (Economides et al. 1994). This reveals that the installation of BPR on casing increases the gas solubility of the oil upstream of the point of installation, followed by the lower oil viscosity. Additionally, the oil viscosity increases with increasing pressure somewhat linearly when the pressure is above the bubble point pressure (McCain 1990). However, this does not imply that the installation of BPR always yields a reverse effect on the oil viscosity when applied to an undersaturated reservoir. If the pressure gradient shows that a pressure becomes lower than the bubble point pressure at a certain point in the reservoir, the effect of lower viscosity commences from that point.

On the other hand, less viscous liquid is perceived to be capable of carrying a lower amount of solid, and the following equations (Arnold and Stewart 2008) are shown to explain the physics behind this general behavior. The drag force acts upward on the sand grain by the liquid due to its downward motion relative to the liquid continuous phase as defined below (Munson et al. 1994):

$F_{\mathrm{D}}=C_{\mathrm{D}} A \rho_{\mathrm{s}}\left(\frac{V_{\mathrm{t}}^{2}}{2 g_{\mathrm{c}}}\right)$

where $C_{\mathrm{D}}$ is the drag coefficient (dimensionless), $A$ is the surface area of the spherical sand grain in $\mathrm{ft}^{2}, \rho_{\mathrm{s}}$ is the density of the sand grain in $\mathrm{lb}_{\mathrm{m}} / \mathrm{ft}^{3}, V_{\mathrm{t}}$ is the terminal velocity of the sand grain in $\mathrm{ft} / \mathrm{s}$, and $g_{\mathrm{c}}$ is the conversion factor for $g\left(32.2 \mathrm{lb} \mathrm{ft} / / \mathrm{b}_{\mathrm{f}} \mathrm{s}^{2}\right)$. The force acting on the body is equal to the sum of the gravity force acting downward and the buoyant force acting upward (Munson et al. 1994):

$F_{\mathrm{B}}=\left(\rho_{\mathrm{s}}-\rho_{\mathrm{l}}\right) \frac{\pi D^{3}}{6}$

where $\rho_{1}$ is the density of the liquid in $\mathrm{lb}_{\mathrm{m}} / \mathrm{ft}^{3}$ and $D$ is the diameter of the sand grain in $\mathrm{ft}$. When the flow is laminar, as the oil flow in heavy oil reservoirs can be described, Stoke's Law applies (Cengel and Cimbala 2009):

$F_{\mathrm{D}}=3 \pi \mu_{1} D V_{t}$

where $\mu_{1}$ is the viscosity of the liquid in $\mathrm{lb}_{\mathrm{f}}-\mathrm{s} / \mathrm{ft}^{2}$. When $F_{\mathrm{D}}$ is equal to $F_{\mathrm{B}}$, the sand grain moves downward due to its higher density at a constant terminal settling velocity, which can be expressed as follows after rearranging the equation, $F_{\mathrm{D}}=F_{\mathrm{B}}$ (Cengel and Cimbala 2009):
$V_{\mathrm{t}}=\frac{\left(\rho_{\mathrm{s}}-\rho_{\mathrm{l}}\right) D^{2}}{18 \mu_{1}}$

Equation 10 shows the form of the relationship between the oil viscosity and the terminal settling velocity of the sand grain. The settling velocity is inversely proportional to the viscosity of liquid, so a decrease in oil viscosity results in a faster terminal velocity. As a result, a larger volume of sand settles down in the reservoir instead of flowing into the wellbore. The latter causes severe pump problems.

Lower basic sediment and water $(B S \& W)$ The second effect of solution gas reduction is the lower BS\&W, which can be explained by the simple Darcy's equation (Slider 1983).

The decrease in oil viscosity leads to a higher oil flow rate. As opposed to the oil, the viscosity of water is not considerably affected by the solution gas or by the pressure. Therefore, the flow rate of water does not change when the flow rate of oil increases. This results in a lower BS\&W or water cut. The actual data of the well taken from AccuMap (v.18.12) shows $4.28 \%$ decease in BS\&W.

Lower in situ oil density The other effect of the solution gas reduction is the lower in situ oil density. As the BPR restricts the flow of vented gas at the surface, this lowers the density of the combination consisting of oil, sand, and slurry. In other words, the gas normally vented through the casingtubing annulus now goes through the tubing due to the flow restriction caused by the BPR. This phenomenon shows that the solution gas reduction also positively functions as the gas lift to displaced the fluids towards the surface.

\section{Effect of produced gas from the gas zone}

The second downhole mechanism that reduces the sand production utilizes the concept of drawdown, which is essentially the pressure difference between the reservoir and the wellbore, $p_{\mathrm{r}}-p_{\mathrm{wf}}$. This mechanism can be explained better in the form of Eqs. 11-13 (Lee 1982):

$p_{\mathrm{wf}}=p_{\mathrm{i}}+162.6 \frac{q_{\mathrm{Rt}}}{\lambda_{\mathrm{t}} h}\left[\log \left(\frac{1688 \varphi c_{\mathrm{t}} r_{\mathrm{w}}^{2}}{\lambda_{\mathrm{t}} t}\right)-\frac{s}{1.151}\right]$

$q_{\mathrm{Rt}}=q_{\mathrm{o}} B_{\mathrm{o}}+\left(q_{\mathrm{g}}-q_{\mathrm{o}} R_{\mathrm{s}}\right) B_{\mathrm{g}}+q_{\mathrm{w}} B_{\mathrm{w}}$

$\lambda_{\mathrm{t}}=\frac{k_{\mathrm{o}}}{\mu_{\mathrm{o}}}+\frac{k_{\mathrm{w}}}{\mu_{\mathrm{w}}}+\frac{k_{\mathrm{g}}}{\mu_{\mathrm{g}}}$

$p_{\mathrm{wf}}$ is the wellbore pressure in psia, $p_{\mathrm{i}}$ is the initial pressure in psia, $\varnothing$ is the porosity, $c_{\mathrm{t}}$ is the total compressibility in $\mathrm{psi}^{-1}, r_{\mathrm{w}}$ is the wellbore radius in $\mathrm{ft}$, $q_{\mathrm{Rt}}$ is the total flow rate in bbl/D, $q_{\mathrm{o}}$ and $q_{\mathrm{w}}$ are the oil flow rate and water flow rate in STB/D, respectively, $q_{\mathrm{g}}$ is the gas flow rate in $M \mathrm{scf} / \mathrm{D}, \lambda_{t}$ is the total mobility in $\mathrm{mD} / \mathrm{cp}$, 
$B_{\mathrm{o}}$ and $B_{\mathrm{w}}$ are the formation volume factor of oil and water in bbl/STB, respectively, $B_{\mathrm{g}}$ is the formation volume factor of gas in bbl/Mscf, $R_{\mathrm{s}}$ is the gas solubility in Mscf/STB, $k_{\mathrm{o}}$, $k_{\mathrm{w}}$, and $k_{\mathrm{g}}$ are the effective permeability of oil, water, and gas in $\mathrm{mD}$, respectively, $\mu_{\mathrm{o}}, \mu_{\mathrm{w}}$, and $\mu_{\mathrm{g}}$ are the viscosity of oil, water, and gas in cp, respectively, $s$ is the skin factor (dimensionless), and $t$ is the time in hours. Applying the concept of multiphase flow using $q_{\mathrm{Rt}}$ (Eq. 12) and $\lambda_{\mathrm{t}}$ (Eq. 13) to the pseudo steady-state reservoir, the equation becomes (Lee 1982):

$\bar{p}-p_{\mathrm{wf}}=\frac{141.2 q_{\mathrm{Rt}}}{\lambda_{\mathrm{t}} h}\left(\ln \frac{0.472 r_{\mathrm{e}}}{r_{\mathrm{w}}}+s\right)$

where $\bar{p}$ and $r_{\mathrm{e}}$ are the average reservoir pressure in psia and drainage radius in $\mathrm{ft}$, respectively. The second term of Eq. 12 on the left-hand side defines the produced gas from the gas zone in the reservoir. When the liquid production, $\left(q_{\mathrm{o}} B_{\mathrm{o}}+q_{\mathrm{w}} B_{\mathrm{w}}\right)$, is kept constant, a decrease in $\left(q_{\mathrm{g}}-q_{\mathrm{o}} R_{\mathrm{s}}\right)$ $B_{\mathrm{g}}$ leads to a smaller $q_{\mathrm{Rt}}$, which in turn results in a smaller pressure difference (see Eq. 14). As the drawdown that supports the sand flow in the reservoir decreases, the volume of sand inflow decreases, and therefore, the downhole pump efficiency is improved. In addition, the oil viscosity decreases due to the solution gas reduction. This, in turn, yields an increase in the total mobility, $\lambda_{t}$, in Eq. 13 and, therefore, further decrease in the drawdown, $\bar{p}-p_{\mathrm{wf}}$, in Eq. 14.

The assumption that the liquid production is not affected by the higher wellbore pressure or smaller drawdown is based on the close analysis of the daily production data of the well. From these data, no definite relationship between the casing pressure and the liquid production is found. Also, the increase in the oil flow rate or lower BS\&W offsets the decrease in the total flow rate. This keeps the total flow rate of liquid somewhat constant throughout the adjustment of casing pressure.

\section{Production data}

The production data of the well were obtained from AccuMap (v.18.12) to analyze the effect of BPR installation on the well performance. The effects can be seen through the increase in production hours (Fig. 5) and reduction in the number of well services required.

Figures 5 and 6 show the increase in GOR after BPR installation and the corresponding overall increase in oil production.

The definitions of calendar daily oil production and average oil production are shown below in the form of Eqs. 15 through 17:

Calendar daily oil production

$$
=\frac{\text { Cumulative monthly oil production }}{\text { Calendar days }}
$$

Average daily oil production

$$
=\frac{\text { Cumulative monthly oil production }}{\text { Production hours }} \times 24
$$

where,

Cumulative monthly oil production

$$
=\text { Monthly produced oil }- \text { monthlyinjectedoil }
$$

The oil injection is the main means of well service so as to restore the production rate by pushing the sand clogging the suction of the pump into the reservoir. The oil, rather than water, is injected since the BS\&W of the candidate well is sufficiently low so that the injection of water may not fit the characteristics of the reservoir. These definitions show that the calendar daily oil production plotted in Figs. 6 and 7 does not account for the shut-in hours of the well caused by well services, whereas the average daily oil production does (see Fig. 7).

However, both parameters are functions of the number of well services implanted in each month, since the cumulative oil production is a function of the injected oil during the well services. As a result, Fig. 7 shows a similar trend. Here GOR represents the ratio of the volume of vented gas through the casing measured for a day to the volume of produced oil in the corresponding day. The volume of solution gas produced by the pressure difference in the tubing is not taken into account. Therefore, the decrease in GOR following the installation of BPR directly reflects the restriction of the vented gas flow through the casing.

As shown in Figs. 6, 7, 8, 9, the candidate well was put back on production in March, 2007, after the re-perforation through the subsurface zone called CUMMGSS. Figure 5 shows that the production hours are low and unsteady prior to the BPR installation. The production hours, however, increase after installing BPR as the well requires fewer well services. Figure 6 divides the production period into the three stages based on the three relatively horizontal GOR lines. It shows that the GOR is relatively high in the first stage where the first sudden drop in the production occurs at the end. The production increases and is stabilized with lower GOR in the second stage, yet the rapid increase in GOR at the end of the second stage triggers a significant drop in the production. In the third stage, the GOR is lowered under the effect of BPR, and the production is relatively stabilized again. The interesting point that is noticeable in Figs. 6, 7, 8, 9 is that, in spite of the BPR installation, the oil production is decreased in the third stage. This production decline is not a result of the BPR installation but a normal trend of the reservoir behavior. When there is no strong drive mechanism such as gas cap and/or aquifer, the production declines corresponding to the reservoir pressure decline. As proof, 
Fig. 5 Effect of BPR installation on production hours (AccuMap, v.18.12)
Fig. 6 Effect of GOR on calendar daily oil production (AccuMap, v.18.12)

\section{Cal. Daliy Oil Production \& Production Hours}

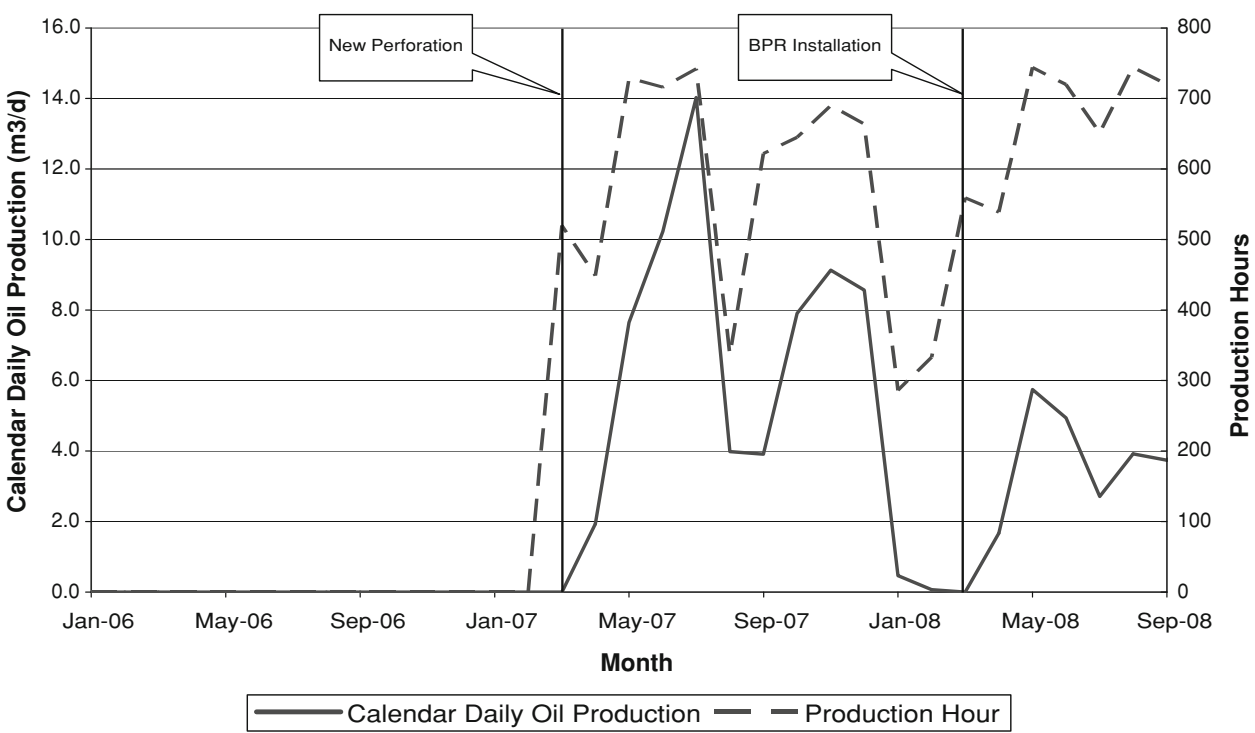

Cal. Daily Oil Production \& GOR

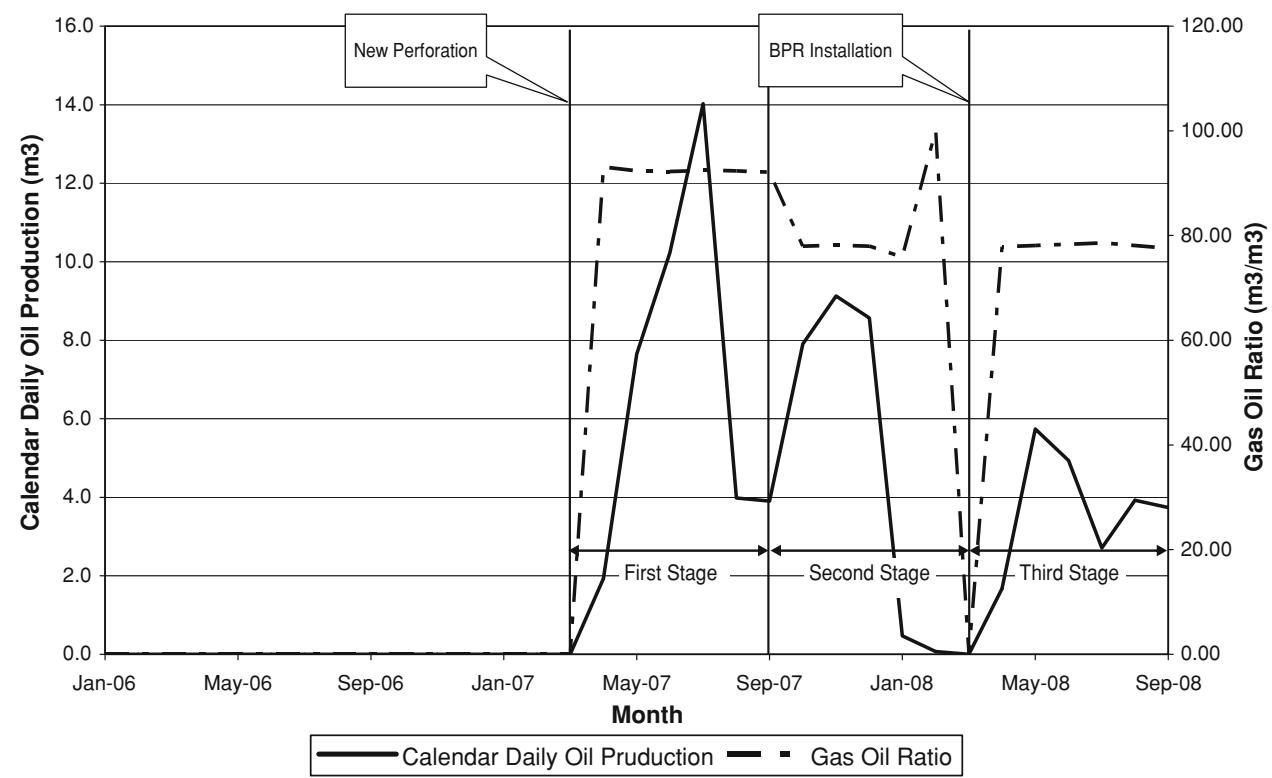

connecting the peaks of the production curve yields a steady decrease in the production regardless of the BPR installation (Fig. 8).

Economic analysis of BPR installation

In order to conduct the economic analysis of BPR installation, the daily production data of the well are analyzed. For the period before the installation of BPR, the data of February and March are used, since the rapid drop in production occurred during these 2 months and raised the need of a solution to the problem. The summary of the analysis is tabulated in Table 2 and also shown in Figs. 10 and 11. This provides a better comparison between the economics before and after the BPR installation.

As shown in Figs. 10 and 11, the number of well services declines dramatically after the BPR installation, followed by a significant increase in the net oil and corresponding profit. If the average values are used, the net oil production has increased approximately six times and the number of well services has decreased by $90 \%$. This results in approximately 34,000 dollars per month increase in profit (assuming $\$ 30.00 / \mathrm{bbl}$ of oil) for each well, showing one million dollars in savings on a monthly basis when the BPR installation is implemented on 30 similar wells. The most important economical aspect of BPR 
Fig. 7 Comparison of average and calculated oil production (AccuMap, v.18.12)
Average Oil Production \& Calendar Oil Production
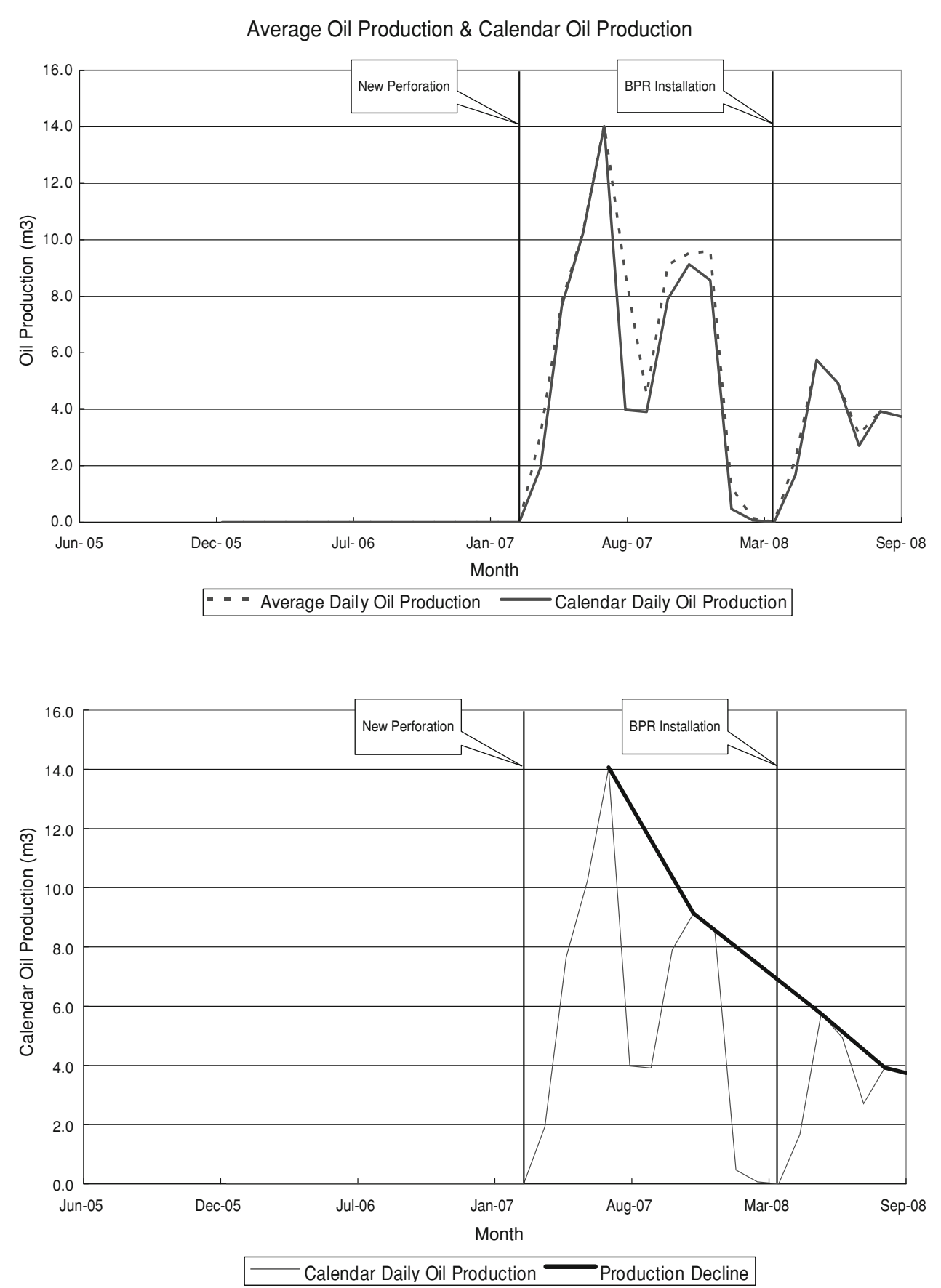

Fig. 8 Normal production decline (AccuMap v.18.12) installation that must be emphasized here is the low CAPEX (Capital Expense) and OPEX (Operational Expense). The capital cost of the BPR installed on the candidate well is $\$ 328.00$, and there is no operating cost involved since additional maintenance and operation required is nearly negligible. Therefore, based on the results obtained, if $30 \mathrm{BPRs}$ were installed on 30 similar wells, the total CAPEX is about \$9840.00.

The relatively low profit in April and July was caused by the pump changes. The average operating life of a PCP is
2-6 months. Also, in a typical case, the old pump that requires a replacement is replaced by a used pump as a means of reducing the CAPEX. Therefore, the repeated pump change in a 3-month term (April and July) during the BPR operation can be considered as a normal PCP operation. In addition, the current information from the field shows that there was no pump change involved after July, 2008. This is because the installation of BPR reduces the need for well services, which in turn reduces the chance of its improper implementation. 
Fig. 9 Number of well services before and after BPR installation

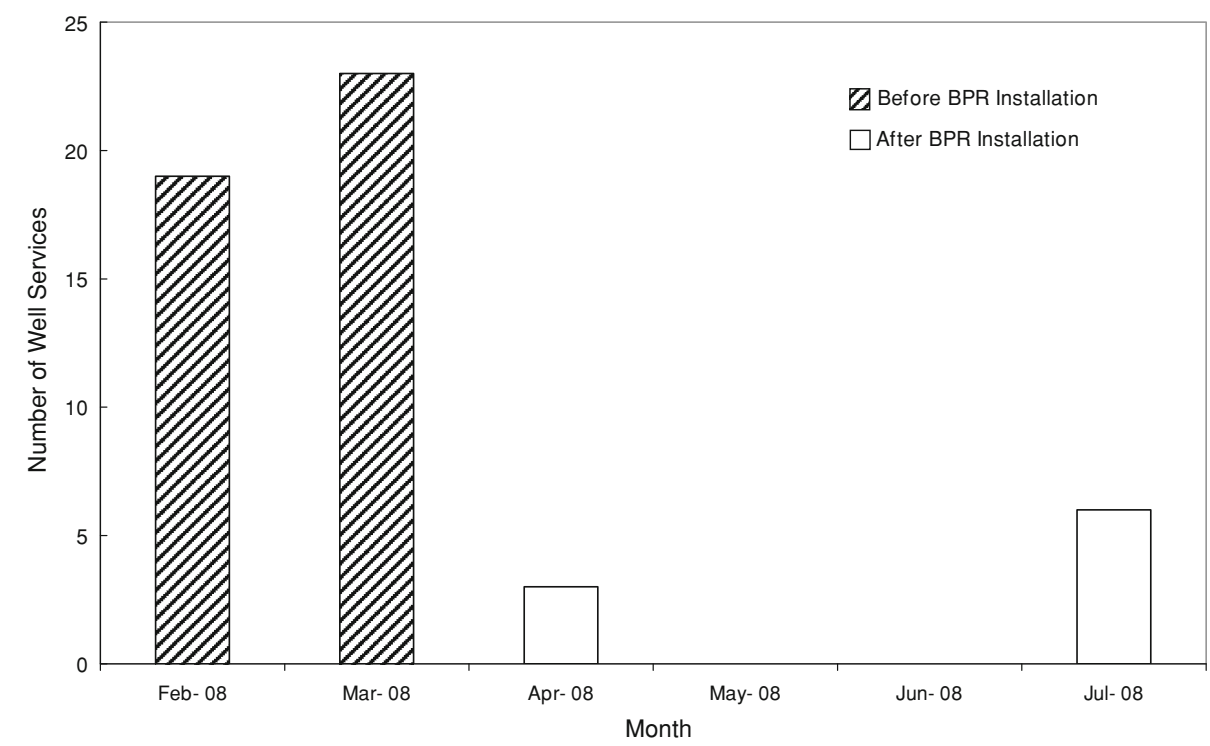

Table 2 Summary of economic analysis for the candidate well

\begin{tabular}{|c|c|c|c|c|c|c|}
\hline Date & Oil produced $\left(\mathrm{m}^{3}\right)$ & Oil injected $\left(\mathrm{m}^{3}\right)$ & Net oil $\left(\mathrm{m}^{3}\right)$ & Number of well services & Shut-in days & Profit (\$) \\
\hline Feb-08 & 155 & 146 & 9 & 19 & 12 & $-15,152$ \\
\hline Mar-08 & 237 & 175 & 62 & 23 & 7 & $-2,951$ \\
\hline Apr-08 & 240 & 30 & 210 & 3 & 8 & 13,626 \\
\hline May-08 & 268 & 0 & 268 & 0 & 0 & 50,570 \\
\hline Jun-08 & 258 & 0 & 258 & 0 & 0 & 48,683 \\
\hline Jul-08 & 131 & 20 & 111 & 6 & 12 & $-10,055$ \\
\hline
\end{tabular}

$\$ 30.00 / \mathrm{bbl}$ of oil is assumed

BPR installed on Mar. 28, 2008

Fig. 10 Profit before and after BPR installation

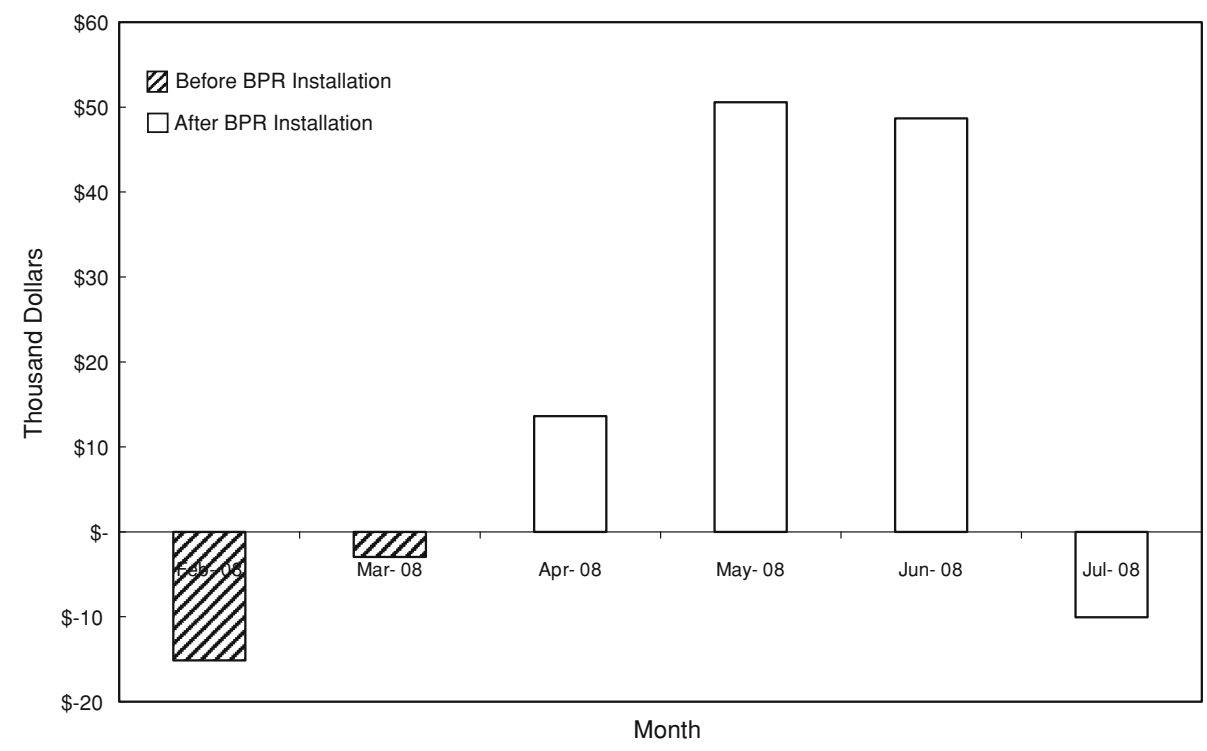

\section{Design of PCP and BPR operation}

Although the installation of BPR on the casing did not directly contribute to the dysfunction of the pump that occurred in April and July, proper operation of the BPR could prevent such losses. These losses raised the need of designing a quick guideline for BPR operation. Thus, based on the downhole mechanism introduced earlier, the 


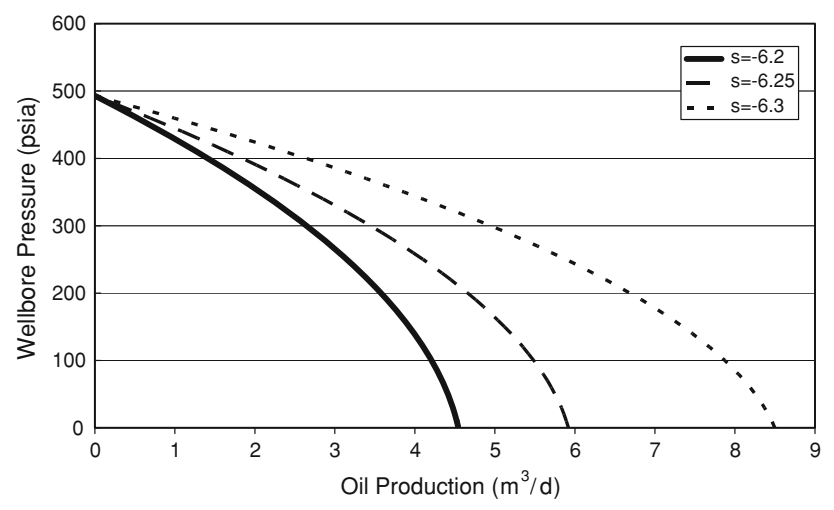

Fig. 11 Inflow performance curve (IPR) curve of the candidate well

methodologies are developed in Section "Methodologies". Also, two examples of improper PCP and BPR operations are described in detail (in Section "Case study") and examined based on the methodologies developed. The actual calculations are based on the reservoir and fluid properties in the location of well.

\section{Methodologies}

When the well is operated with BPR on the casing, the decision making process, in an attempt to optimize the well production, is more intense than the situation without BPR. Especially if the history of the well shows downhole sand problems, a close study of the well and reservoir behavior is required.

\section{Generation of inflow performance curve (IPR curve)}

The IPR curve is an essential tool in production engineering, which is widely used for various purposes such as anticipating the oil production at certain wellbore pressures. For a reservoir at pseudo-steady state, the following equation is given by Economides et al. (1994) for the generation of the IPR curve:

$s_{\mathrm{o}}=\frac{k k_{\mathrm{ro}} h \bar{p}\left[1-0.2\left(p_{\mathrm{wf}} / \bar{p}\right)-0.8\left(p_{\mathrm{wf}} / \bar{p}\right)^{2}\right]}{254.2 B_{\mathrm{o}} \mu_{\mathrm{o}}\left[\ln \left(0.472 r_{\mathrm{e}} / r_{\mathrm{w}}\right)+s\right]}$

where $p_{\mathrm{wf}}$ is the wellbore pressure in psia, $\bar{p}$ is the average reservoir pressure in psia, $r_{\mathrm{w}}$ is the wellbore radius in $f t, q_{\mathrm{o}}$ is the oil flow rate in STB/D, $B_{\mathrm{o}}$ is the formation volume factor of oil in bbl/STB, $k$ is the absolute permeability in $\mathrm{mD}, k_{\mathrm{ro}}$ is the relative permeability of oil, $\mu_{\mathrm{o}}$ is the viscosity of oil in $c$ p, and $s$ is the skin factor (dimensionless). Assuming $k_{\mathrm{ro}}=0.4$ for a typical heavy oil reservoir in Alberta, the live oil viscosity at the reservoir conditions $\left(\mu_{\mathrm{o}}\right)$ is the only unknown parameter in this equation. The correlations are used to determine the in situ oil viscosity (McCain 1990; Economides et al. 1994). The IPR curve can be generated at different skin factors, which is shown in Fig. 11.

\section{Generation of viscosity curve}

The viscosity curve is created by plotting viscosity versus pressure so as to examine the relationship between the oil viscosity and the wellbore pressure. Since the wellbore pressure is lower than the bubble point pressure, the correlations for the pressure below the bubble point are employed. Figure 12 shows the viscosity curve.

\section{Calculating wellbore pressure}

The wellbore pressure is one of the most important properties of a well in petroleum engineering because it is directly related to the oil production. Especially in the case of PCP and BPR operation, the wellbore pressure plays a very significant role in estimating the oil viscosity at the wellbore conditions. The methodology of calculating the wellbore pressure is shown in detail through the following steps:

Step 1: Obtaining the fluid level in the casing and the casing pressure Step 2: Estimation of the heights of gas and liquid columns In order to calculate the heights of the gas and liquid columns, the true vertical depth (true vertical depth refers to the vertical length of the well from the surface) and the measured depth of the formation (measured depth refers to the actual length of the well from the surface) should be obtained from AccuMap. The total measured depth of the well can be calculated using the following equation:

MD $=$ Number of tubing yoints

$\times$ average lengh of one tubing joint

where MD is the measured depth.

Step 3: Calculation of the oil density The density of the oil is calculated at the reservoir temperature since the oil column is located at the bottom of the well. The Gros correlation (see Green and Whilhite 1998) is used to estimate the density of oil in the oil column. In this correlation, the effect of pressure is ignored, and the temperature is in ${ }^{\circ} \mathrm{F}$. The Gros correlation is

$\rho_{\mathrm{o}}=\rho_{\mathrm{oR}}-C_{1}(T-60)+C_{2}(T-60)^{2}$

Where

$\rho_{\mathrm{oR}}=62.4278\left[141.5 /\left(131.5+{ }^{\circ} \mathrm{API}\right)\right]$

$C_{1}=0.0133+152.4 \rho_{\mathrm{oR}}^{-2.45}$

and 
Fig. 12 Viscosity curve of Well 2B-35-55-6

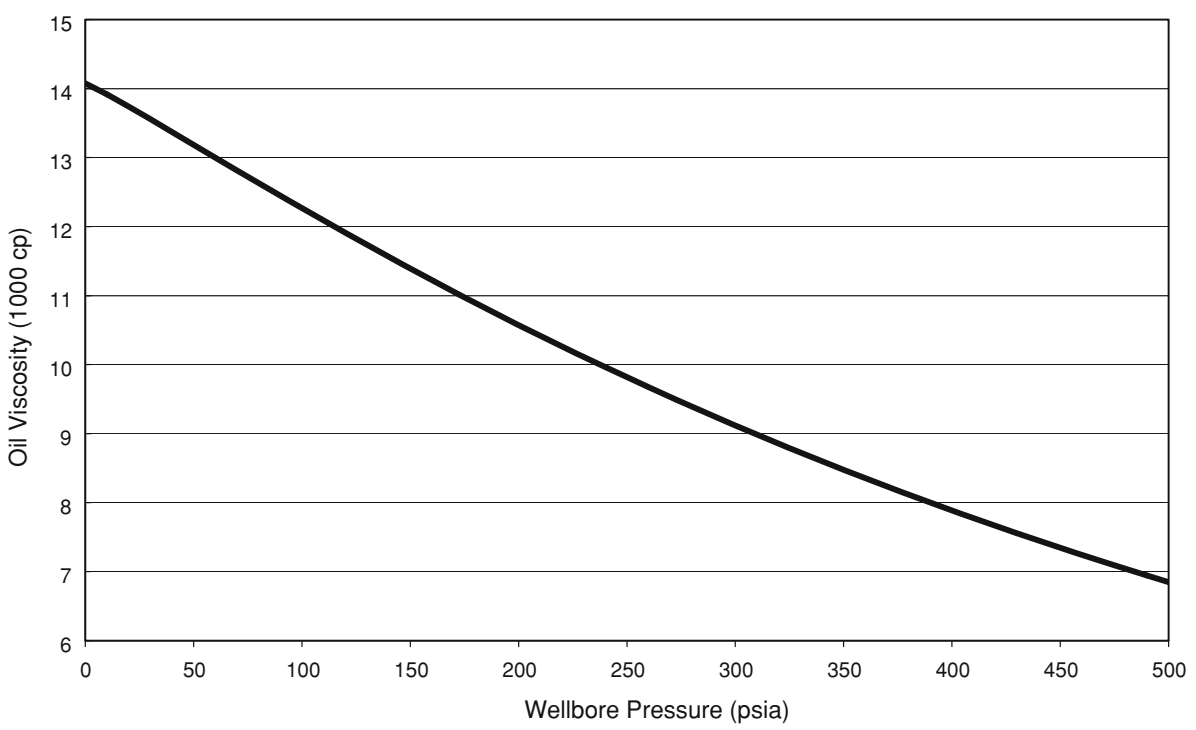

$C_{2}=0.0000081-0.0622 \times 10^{-\left(0.0764 \rho_{\mathrm{oR}}\right)}$

$h_{\mathrm{g}}=\frac{1}{\left(\rho_{1}-\rho_{\mathrm{g}}\right) g}\left(\frac{\mathrm{RPM}}{C \times q_{1}}+P_{\mathrm{c}}\right)$

Step 4: Calculation of the liquid density The density of liquid accounts for the density of water of which the continuous oil phase consists and is calculated using the following equation (Ahmed and McKinney 2005):

$\rho_{1}=\frac{\mathrm{WOR} \rho_{\mathrm{w}}+B_{\mathrm{o}} \rho_{\mathrm{o}}}{\mathrm{WOR}+B_{\mathrm{o}}}$

Step 5: Calculation of the gas density The density of the gas at the casing pressure and the reservoir temperature is calculated using the following equation (Green and Willhite 1998):

$\rho_{\mathrm{g}}=0.093 \frac{(M W) P}{T Z}$

where, $\rho_{\mathrm{g}}$ is the density of gas in $\mathrm{lb}_{\mathrm{m}} / \mathrm{ft}^{3}, P$ is the pressure in psia, $T$ is the temperature in ${ }^{\circ} \mathrm{R}, Z$ is the gas compressibility factor, and $M W$ is the gas molecular weight. The gas compressibility can be obtained from the chart using the pseudo-reduced properties defined as (McCain 1990).

\section{Relationship between fluid level and pump RPM}

The relationship between the pump speed and fluid level is somewhat important in terms of BPR operation, since a decrease in the fluid level corresponding to a certain increase in the pump speed provides the operator the range of the pump speed that can be attained. The equation given below describes the relationship between the pump speed, power, flow rate, and pressure difference across the pump (Economides et al. 1994): where $C$ is a constant and $q_{1}$ is the liquid production rate.

Case study

Two examples of improper BPR operation, which triggered the pump change in April and July, are studied and described in detail in the following subsections (Sections "PCP and BPR operation during production period: improper BPR operation in April 2008" and "PCP and BPR operation before production started: improper BPR operation in July 2008"). Also, these sections include the possible solutions based on the methodologies developed.

$P C P$ and BPR operation during production period: improper BPR operation in April 2008

In order to optimize the well production, the operator of the candidate well increased the pump speed when the casing pressure was kept constant. The lower wellbore pressure increased the production rate as well as the sand production. The amount of sand flowing into the wellbore exceeded the capacity of the pump, and the pump finally got 'sanded-up'. The sand, which flows into the wellbore but cannot be lifted by the PCP, is accumulated at the wellbore. Sanded-up situation occurs when the maximum applied torque cannot turn the rotor due to the accumulated sand. This situation is also referred to as 'torqued-up'. After the Coiled tubing unit (CTU) job, the pump became no longer usable and, therefore, it had to be changed. The improper implementation of CTU job is harmful to PCP 
because the inserted coiled tubing may damage the stator. The operator could have increased the casing pressure before increasing the pump speed. However, the operator decided to keep the casing pressure constant because the fluid level was relatively low. In fact, the operator was not sure how much of the fluid level would be decreased by increasing the casing pressure and did not intend to cause the dry condition for the pump.

Solution A decision must be made in an attempt to optimize the well production when the operator is not sure if increasing the pump speed or lowering the casing pressure (to secure the higher fluid level in the casing) would cause any trouble by sand. In this case, the operator faces two options, depending on the fluid level in the casing: (i) increasing pump speed with adjusting casing pressure and (ii) increasing pump speed without adjusting the casing pressure. First, the current wellbore pressure has to be calculated using the methodology introduced in Section "Methodologies". Then, the methodology described in Section "Methodologies" should be used to predict the oil production and the increase in oil viscosity, respectively, at a certain increase in the wellbore pressure. Based on the knowledge of the anticipated production rate, the fluid level at any combination of the pump speed and casing pressure can be estimated using Eq. 26. The methodologies introduced in this article would help the operator's decision making process. However, the operator's past experience with the well must be added so as to accomplish the best result.

\section{$P C P$ and BPR operation before production started: improper BPR operation in July 2008}

The candidate well had to be shut-in due to the drilling operation near the area. When a well is shut-in, although the flow at the surface is stopped, it takes some time for the wellbore pressure to stabilize. In other words, the sand keeps flowing in the reservoir and accumulates at the wellbore for some time during the shut-in period. This shows that a well service is essential before restarting a 'trouble' well. When the drilling operation was finished, a flush-by was called in for the candidate well. The flush-by pulls out the rotor of the stator and injects oil or water into the tubing in order to push the sand away from the wellbore. Well services normally require the gas to be vented from the casing, in which case the BPR could not apply pressure on the casing after the flush-by. The operator did not want to wait for the casing gas to be accumulated in the casing-tubing annulus to increase the cumulative production. However, when the well was started without the BPR functioning, the pump was sanded-up immediately and eventually resulted in a pump change.
Solution If the operator does not want to delay the startup of the well to maximize the production, a non-condensable gas such as nitrogen can be injected through the annulus to hasten the gas build-up process.

\section{Summary, conclusions, and recommendations for future developments}

After analyzing various techniques that can be implemented to minimize sand production and improve the well productivity in heavy oil reservoirs, the following conclusions can be drawn:

1. Screens can be installed to minimize sand production and reduce pump shut-in periods; however, the well might still not be economical due to the high cost of installing screens and the workover that is required to clean them periodically.

2. Gravel packs, screens, and wire-wrapped casings increase the skin factor that is contrary to CHOPS that decreases the skin factor by forming wormholes. CHOPS was the primary mode of production for the well under consideration.

3. The flow rate of the well prior to screen installation and after screen installation is showing at least a $5 \%$ reduction in flow rate.

4. BPR Installation on the casing reduces the viscosity of oil at the wellbore. The oil viscosity is inversely proportional to the terminal settling velocity of the sand grains. This shows that the decrease in the oil viscosity increases the settling velocity of the sand grains, and, therefore, a smaller amount of sand flows into the wellbore.

5. The decrease in the in situ oil viscosity results in a lower BS\&W. This is because the viscosity of water is not affected by the BPR. As a result, the average $\mathrm{BS} \& \mathrm{~W}$ of the candidate well was decreased by $4.28 \%$ over the 6 months period following the BPR installation.

6. The solution gas reduction results in a lower in situ oil density. The gas normally vented through the casing-tubing annulus flows through the tubing after the BPR installation. This phenomenon functions as gas lift and helps the oil production.

7. The BPR installed on the casing yields a smaller drawdown as it applies higher pressure on the wellbore. Although the smaller drawdown decreases the production rates of gas, liquid, and sand, the effect on the oil production is relatively small because the BS\&W decreases.

8. BPR Installation on the casing is applicable to both undersaturated and saturated reservoirs. This is because in CHOPS most of the production occurs 
near the wellbore, where the pressure is obviously lower than the bubble point pressure.

9. The production data of the candidate well shows the increase in production hours after the BPR installation. This corresponds to the increase in the oil production. If $30 \mathrm{BPRs}$ were installed on 30 similar wells, the $\$ 9840$ of CAPEX would result in a profit of approximately 1 million dollars per month. This is based on an oil price of $\$ 30.00 / \mathrm{bbl}$ and the BPR cost of $\$ 328.00 /$ each. The operating cost of the BPR is negligible.

10. For future developments, the following tasks are recommended to be carried out for further studies of installing BPR on heavy oil wells: (i) the applicability of installing BPR on a heavy oil well producing a high volume of water, (ii) determining the amount of sand that a PCP is capable of lifting under certain conditions (i.e., at different wellbore pressures and oil viscosities), and (iii) the prediction of sand production as the well is being depleted.

Open Access This article is distributed under the terms of the Creative Commons Attribution License which permits any use, distribution, and reproduction in any medium, provided the original author(s) and the source are credited.

\section{References}

Aghabarati H, Dumitrescu C, Lines L, Settari A (2008) Combined reservoir simulation and seismic technology, a new approach for modeling CHOPS. In: International thermal operations and heavy oil symposium, Calgary, AB, Canada

Ahmed T, McKinney PD (2005) Advanced reservoir engineering. Elsevier, USA

Arnold K, Stewart M (2008) Surface production operators design of oil handling systems and facilities, 3rd edn. Elsevier, Burlington

Cavender TW (2004) Heavy oil development: summary of sand control and well completion strategies used with multilateral applications. In: IADC/SPE Asia pacific drilling technology conference and exhibition, Kuala Lumpur, Malaysia

Cengel YA, Cimbala JM (2009) Fluid mechanics: fundamentals and applications, 2nd edn. McGraw Hill Higher Education, New York

Craft BC, Hawkins MF, Terry RE (1990) Applied petroleum reservoir engineering. Prentice Hall Inc, New Jersey

Economides MJ, Hill AD, Ehlig-Economides C (1994) Petroleum production systems. Prentice Hall Inc., Englewood Cliffs

Golan M, Whitson C (1991) Well performance, 2nd edn. Prentice Hall, New Jersey

Green DW, Willhite GP (1998) Enhanced oil recovery. SPE textbook series, vol 6. Society of Petroleum Engineers, Richardson

Halliburton Products and Services. Accessed 1 March 2009. http:// www.halliburton.com/public/cps/contents/Books_and_Catalogs/ web/SandControlTOC.pf

Lee J (1982) Well testing. SPE textbook series, vol 1. Society of Petroleum Engineers, Richardson

McCain WD Jr (1990) The properties of petroleum fluids, 2nd edn. PennWell Publishing Company, Tulsa

Munson BR, Young DF, Okiishi TH (1994) Fundamentals of fluid mechanics. Wiley, New York

Penberthy WL, Shaughnessy CM (1992) Sand control. SPE series on special topics, vol 1. Richardson

Revard JM (1995) The progressing cavity pump handbook. PennWell Publishing Company, Tulsa

Slider HC (1983) Worldwide practical petroleum reservoir engineering methods. PennWell Publishing Company, Tulsa 